\title{
Application of the Double Pulse Potential Chronoamperometry Technique to Modify the ITO Electrode Surface
}

\author{
Salvador García-Esparza, Leonor M. Blanco, Sylvain Bernès \\ División de Estudios Superiores, Facultad de Ciencias Químicas, Universidad Autónoma de \\ Nuevo León, Guerrero y Progreso S/N, Col. Treviño, C.P. 64570, Monterrey, N.L., México
}

Received 16 April 2008; accepted 18 September 2008

\begin{abstract}
This paper proposes the application of the Double Pulse Potential Chronoamperometry (DPPC) technique to modify the ITO electrode surface in order to increase the electrode activity for chlorophenol detection. This technique consists in the application of two sets of potential pulses (anodic and cathodic). We used Ni-triethylenediamine as the electrode-modifying agent. We characterized the modified electrodes using SEM and Cyclic Voltammetry (CV), and determining the amount of film immobilized over the electrode area. We also applied CV to detect 2,4-dichlorophenol using the chemically modified electrodes (CMEs). The application of DPPC led to CMEs with a higher capacity to detect 2,4-DCP than that of the CMEs obtained by Chemisorption and CV.
\end{abstract}

Keywords: ITO, modified electrodes, cyclic voltammetry, double pulse potential chronoamperometry, 2,4-dichlorophenol.

\section{Introduction}

Nowadays, it is important to have precise and sensitive analytical techniques to determine the quantity of pollutants present in the environment. This particular need results from the requirement of regulating the usage of hazardous and very pollutant substances. Such substances are widely used because of their properties, but in most cases they bring more troubles than benefits. A very clear example is the chlorophenols, which have antimicrobial properties; this is the reason why their use has been increased recently. Among the factors that make the chlorophenols so toxic, are the level of chlorination, the position of the chlorine atoms respect of the $\mathrm{OH}$ group, and also the fact of that these substances are recalcitrant.

\footnotetext{
* Corresponding author. E-mail address: leonyjerez@gmail.com
} 
In this group we can find the 2-chlorophenol (2-CP), 4-chlorophenol (4-CP), 2,4dichlorophenol (2,4-DCP), 2,4,6-trichlorophenol (2,4,6-TCP), and the pentachlorophenol (PCP), which is the most important of a group of nineteen substances [1].

A viable alternative to detect such chemicals is the use of an electrochemical sensor. However, the use of conventional (or unmodified) electrodes as electrochemical sensors has several disadvantages because of the slow nature of the organic electrodic reactions. For this reason, it is necessary modify these electrodes by introducing into the system a catalyst that could be in dissolution or immobilized on the electrode surface. The catalyst immobilized on the electrode surface produces a Chemically Modified Electrode (CME).

Some CMEs have been reported to be capable of breaking down some compounds; other CMEs are able to detect the presence of an organic pollutant; among the modifying agents applied to these CMEs we can find metallic complexes, such as $\mathrm{Ni}$ (salen), $\mathrm{Ni}$ (cyclam) [2], Cobalt and Nickel Metalloporphyrins [2], Cobalt phtalocyanines [3], Schiff's bases [3], and Ruthenium Porphyrins, which have been used in the oxidation of sulfite and nitrate [4] and 2,3-dimetil-N,N'-bis(salicildene)butane-2,3-diaminatenickel(II) [5].

Present day methods available to modify electrodes are [6]: a) Direct Absorption, b) Covalent Immobilization, c) Electrode Matrix Modification, and d) Polymer Immobilization. The Polymer Immobilization method can be carried out by applying electrochemical techniques that form the polymer from its monomers. This technique has several advantages; one of them is the reaction control that allows following the course of the reaction.

The Polymer Immobilization method is commonly used to modify the surface of Indium Tin Oxide (ITO) with a typical weight composition of $90 \%$ of $\operatorname{In}_{2} \mathrm{O}_{3}$ and $10 \%$ of $\mathrm{SnO}_{2}$, and Glassy Carbon.

In this paper we propose the application of the Double Pulse Potential Chronoamperometry (DPPC) technique to modify an ITO surface, using Nickel Triethylenediamine as the modifying agent. We also compare this technique with other modification techniques, such as, Chemisorption and Cyclic Voltammetry.

\section{Experimental part}

We applied the following methodology: a) synthesis and characterization of the nickel triethylenediamine complex; b) electrode modification applying chemisorption, double pulse potential chronoamperometry and polymer immobilization by cyclic voltammetry; c) evaluation of the resulting electrode modification using cyclic voltammetry $(\mathrm{CV})$ in an environment free from the modifying agent; d) characterization of the generated film by means of scanning electron microscopy (SEM); and finally, e) quantification of the film immobilized on the electrode surface using the coulombimetric technique. We used an Epsilon Potentiostat from BAS to apply the electrochemical techniques. 
Synthesis and characterization of $\mathrm{Ni}(\text { en })_{3} \mathrm{Cl}_{2} \cdot 2 \mathrm{H}_{2} \mathrm{O}$

We synthesized the complex tris(ethylenediamine)nickel(II) dihydrate chloride by means of the reaction between ethylenediamine and $\mathrm{NiCl}_{2} \cdot 6 \mathrm{H}_{2} \mathrm{O}$ in a molar ratio of 3:1; the product was crystallized on ethanol. We applied single crystal XRay diffraction to characterize the resulting solid, a homogenous purple powder. We used a Bruker P4 diffractommeter to analyze a single crystal of the synthesized complex (with dimensions of $0.24 \times 0.16 \times 0.16 \mathrm{~mm}$ ) under the following conditions: room temperature, $\lambda$ of $0.71063 \AA\left(\mathrm{K}_{\alpha} \mathrm{Mo}\right), 30 \mathrm{kV}, 30 \mathrm{~mA}$, and a maximum angle (20) of 56 degrees.

Blank analysis

In order to verify the modification of the ITO surface by means of the CV experiments, we used a solution of $\mathrm{NaOH} 0.1 \mathrm{M}$ as a blank, with an unmodified ITO as working electrode. We also used an unmodified ITO working electrode as the blank for the SEM analysis.

\section{Electrode preparation}

In each experiment we applied a two-stage process to clean the ITO: a) sonication for at least 30 minutes using a solution of $1 \%$ in Alconox; and b) sonication for 30 minutes in ethanol.

Electrode chemisorption was carried out by means of a $2^{2}$ experiment design, where we included as the factors the modifying agent concentration, and the time of contact between the modifying agent and the ITO surface. The levels of these factors were: 3 and $5 \mathrm{mM}$ for the concentration of the nickel complex solution, and 30 and 60 minutes for the time of contact. The working $\mathrm{pH}$ was 13, because, according to [7], this $\mathrm{pH}$ value is the optimal condition for the improvement of the surface modification process. The response of the system was set as qualitative, based on the fact that we wanted to know the effect of altering these factors on the general properties of the immobilized film, such as physical and chemical, which are not a numerical value.

Finally, we applied CV to the electrodes in order to verify the modification of their surface induced by chemisorption. We used CME (modified ITO) as the working electrode, $\mathrm{Ag} / \mathrm{AgCl}$ as the reference electrode, $\mathrm{Pt}$ as the auxiliary electrode and $\mathrm{NaOH} 0.1 \mathrm{M}$ as the supporting electrolyte.

The CV was carried out under the conditions reported in [7]: nickel complex concentration of $3 \mathrm{mM}, \mathrm{pH} 13(\mathrm{NaOH} 0.1 \mathrm{M})$, a scan rate of $250 \mathrm{mV} / \mathrm{s}$, and scanning from $0 \mathrm{mV}$ to $+800 \mathrm{mV}$. We verified the electrode modification using the same methodology and the same experimental technique.

\section{Application of DPPC to modify the ITO electrode surface}

The selected technique, Double Pulse Potential Chronoamperommetry (DPPC), consists in the application of two sets of potential pulses: an anodic pulse set and a cathodic pulse set. The pulse magnitudes were determined by applying CV to a solution of the nickel complex using the experimental conditions described above. The resulting pulse magnitudes were $+650 \mathrm{mV}$ for the anodic pulse and $+380 \mathrm{mV}$ for the cathodic pulse. 
We selected the following experimental conditions for DPPC: 5 minutes of electric field application, and $3 \mathrm{mM}$ for the nickel complex concentration. Since these conditions are similar to the conditions used in the CV method, it is possible to compare the electrode modification results obtained by the application of both methods. We distributed the electric field application time in five cycles of 64 seconds (32 seconds of anodic pulses and 32 seconds of cathodic pulses). Fig. 1 depicts a typical chronoamperogram of the electrode modification by DPPC.

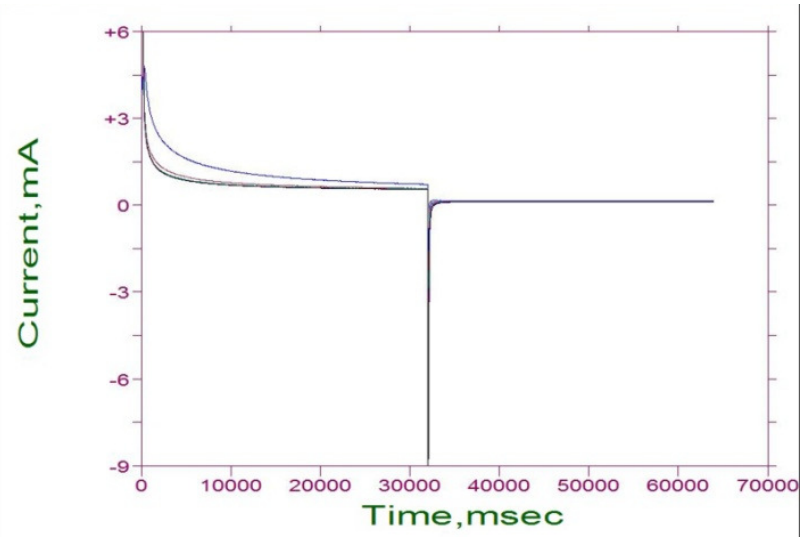

Figure 1. Chronoamperogram of the modification of the ITO electrode by DPPC.

\section{SEM characterization}

We applied SEM analysis to several samples in order to determine their surface morphology after the modification. We also conducted a mapping of nickel and nitrogen atoms in order to determine the complex distribution on the electrodic surface, since nitrogen comes exclusively from existence of the complex on the surface, tracking nickel and nitrogen atoms will reveal the complex presence on ITO surface. Finally, we applied energy dispersive spectroscopy to determine the relative quantities of nickel and nitrogen.

Determination of the quantity of material immobilized on the electrodic surface per electrode surface unit

We used the coulombimetric technique to determine the quantity of material immobilized on the electrodic surface. We conducted an exhaustive electrolysis to a CME of known area, holding a constant potential. We determined the value of this potential by applying a $\mathrm{CV}$ to the same $\mathrm{CME}$ in a solution of $\mathrm{NaOH} 0.1$ M. We chose for the coulombimetric test a potential value, which is higher than the potential of the voltammetric peak. The chosen potential corresponds to the oxidation of the $\mathrm{Ni}^{2+}$ present in the film to $\mathrm{Ni}^{3+}$ under conditions of diffusion control, which means, that no other process than nickel oxidation is occurring at that point.

In the coulombimetric test we applied potential during the time required for the current to decay to $1 \%$ of its initial value, which is a quantity that can certify that most of the electroactive available material is consumed. Nitrogen bubbled into the dissolution at a given flow rate provided an adequate stirring. The software of the Epsilon potentiostat from BAS used for this technique reports the total 
charge (Q) that flows through the electrochemical system in the time of application. Knowing Q and using the Faraday's Law we can determine the quantity of electroactive material present in the CME, expressed in mole. Since we know the electrode geometric area, we can calculate the quantity of material $\Gamma$, in mole per $\mathrm{cm}^{2}$.

\section{2,4-dichlorophenol detection}

We also applied CV for detection of 2,4-DCP. In this case we used CV to compare the activity of the CME to that of ITO (as an unmodified electrode). The experimental conditions were the following: $100 \mathrm{ppm}$ of 2,4-DCP, ITO or $\mathrm{CME}$ as working electrodes; $\mathrm{Ag} / \mathrm{AgCl}$ as the reference electrode; $\mathrm{Pt}$ as the auxiliary electrode; a scan rate of $100 \mathrm{mV} / \mathrm{s}$; scanning from open circuit potential to $1000 \mathrm{mV}$ during one cycle; two values of $\mathrm{pH}, 8.2$ and 5, for both sample and blank.

\section{Results}

Using the results of the X Ray diffraction by monocrystal analysis we determined the unit cell of the synthesized complex, which corresponds to [Ni(en $\left.)_{3}\right] \mathrm{Cl}_{2} \cdot 2 \mathrm{H}_{2} \mathrm{O}$, as reported by Hai Feng et al. [8]. Table 1 shows the unit cell parameters. We also found that the complex has a monoclinic crystalline structure belonging to the Cc spatial group.

Table 1. Unit cell parameters for the complex $\left[\mathrm{Ni}(\mathrm{en})_{3}\right] \mathrm{Cl}_{2} \cdot 2 \mathrm{H}_{2} \mathrm{O}$.

\begin{tabular}{|c|c|}
\hline Parameter & {$\left[\mathrm{Ni}(\text { en })_{3}\right] \mathrm{Cl}_{2} \cdot 2 \mathrm{H}_{2} \mathrm{O}$} \\
\hline $\mathrm{a}$ & $26.1743(3) \AA$ \\
\hline $\mathrm{b}$ & $13.889(2) \AA$ \\
\hline $\mathrm{c}$ & $12.889(2) \AA$ \\
\hline$\alpha$ & $90.0^{\circ}$ \\
\hline$\beta$ & $93.163^{\circ}$ \\
\hline$\gamma$ & $90.0^{\circ}$ \\
\hline Volume & $4,678.53 \AA^{3}$ \\
\hline
\end{tabular}

\section{Electrochemical experiments}

We used the $\mathrm{CV}$ blank analysis to determine the working range, which is the potential range where no faradaic event is present. The working range was from $800 \mathrm{mV}$ to $+1000 \mathrm{mV}$ in this case. (All the potentials are referred to $\mathrm{Ag} / \mathrm{AgCl}$ electrode). In the SEM blank analysis, made to an unmodified electrode, we obtained a homogeneous surface. This analysis was made at $30 \mathrm{KeV}$ and 1 torr of pressure.

In the electrode modification by chemisorption, it was observed that the experiment with the highest levels of the variables studied led to the CME with the best physicochemical properties. This conclusion is supported by the parameters determined in the test of the electrode modification: the peak average current was $0.15 \mathrm{~mA}$ for the experiments with the lowest-level variables, and it was $0.512 \mathrm{~mA}$ for the experiments with the highest-level variables. In addition, 
the results obtained by the SEM technique confirm this conclusion by showing important differences between the CME produced by the application of the different levels for each factor. Table 2 shows information relevant to prove the presence of the complex on the ITO surface, where EDS prove the existence of $\mathrm{Ni}$ and $\mathrm{N}$ atoms. However, the chemisorptions technique had no reproducibility, possibly due to the long time of immersion under a strong basic solution that could have degraded the ITO film.

Table 2. Results of SEM and EDS analysis of the immobilized film obtained by chemisorption.

\begin{tabular}{|c|c|c|c|c|c|c|}
\hline Exp & $\begin{array}{c}\text { Conc. } \\
(\mathrm{mM})\end{array}$ & $\begin{array}{c}\mathrm{t} \\
(\mathrm{h})\end{array}$ & Appearance & Distribution & $\% \mathrm{Ni}$ & $\% \mathrm{~N}$ \\
\hline 1 & 0.3 & 0.5 & Arborescence & Heterogeneous & 0.49 & 3.31 \\
\hline 2 & 0.5 & 0.5 & Arborescence & Heterogeneous & 0.34 & 2.36 \\
\hline 3 & 0.3 & 1 & Grains & Heterogeneous & 2.98 & 3.18 \\
\hline 4 & 0.5 & 1 & Grains & Homogeneous & 19.99 & 6.52 \\
\hline
\end{tabular}

In the modification by means of the $\mathrm{CV}$ we found that the selected conditions led to the production of CMEs with nickel triethylenediamine. This conclusion is supported by the presence of the modification typical current peaks in the voltammograms (see Table 3). The SEM analysis also shows a heterogeneous surface due to the modification.

The application of DPPC to modify an electrode led to a CME. This conclusion is supported by the VC and SEM results shown in Fig. 2.
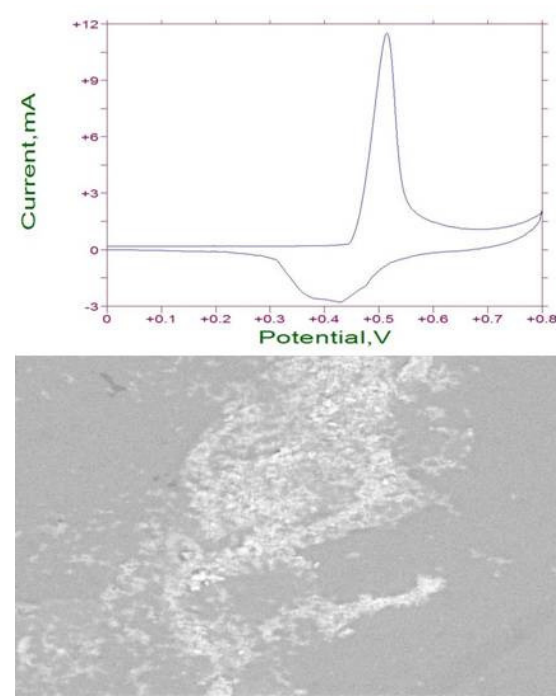

Figure 2. Determination of the electrode modification using DPPC and SEM image at $500 x$ of the CME obtained by DPPC. 
Table 3. Potential peak differences and peak oxidation currents obtained in the test to verify the modification of the electrodes.

\begin{tabular}{|c|c|c|}
\hline Technique & $\Delta \mathrm{E}_{\mathrm{p}}(\mathrm{mV})$ & $\mathrm{ip}_{\mathrm{ox}}(\mathrm{mA})$ \\
\hline Chemisorption & 193 & 0.512 \\
\hline DPPC & $84.12_{ \pm 12.8}$ & $9.8_{ \pm 0.88}$ \\
\hline Cyclic voltammetry & $202.9_{ \pm 20.5}$ & $6.9_{ \pm 0.91}$ \\
\hline
\end{tabular}

Table 4 summarizes the results of the determination of the quantity of film immobilized on the ITO surface, where a factor of 10 can be observed from the chemisorptions to the electrochemical techniques; this could be justified possibly to the fact that in the electrochemical techniques is likely for a polymer to be formed on the surface, while in the chemisorptions that is not possible, leading to the formation of a monolayer.

\section{2,4-dichlorophenol detection}

We tried to detect 2,4-DCP by CME at $\mathrm{pH} 8.2$ as recommended in [7]. However, the detection using a CMEs was not successful, since the characteristic faradaic current peaks were not observed. For this reason, we applied CME at a lower $\mathrm{pH}$ value ( $\mathrm{pH} 5$ ), and using fresh-prepared CMEs produced by $\mathrm{CV}$ and DPPC as working electrodes (see Fig. 3). The CME prepared by chemisorption was not used for this test because of the non-reproducibility of this modification technique. We conducted an additional $\mathrm{CV}$ experiment in order to evaluate the system, using reticulated glassy carbon as the working electrode. This experiment can serve as a reference, because the detection of 2,4-DCP by CV using this electrode has been reported as successful. The experimental conditions were the same as those reported in [7].

Table 4. Quantity of immobilized film per electrode surface unit.

\begin{tabular}{|c|c|}
\hline Technique & $\Gamma\left(\mathrm{mol} / \mathrm{cm}^{2}\right)$ \\
\hline Chemisorption $(5 \mathrm{mM}, 1 \mathrm{~h})$ & $3.65 \times 10^{-5}$ \\
\hline DPPC $(3 \mathrm{mM}, 5$ cycles $)$ & $3.75 \times 10^{-4}$ \\
\hline Cyclic voltammetry & $3.62 \times 10^{-4}$ \\
\hline
\end{tabular}

Table 5 shows the potential peak differences and peak oxidation currents corresponding to the oxidation of 2,4-DCP on the electrodes modified by CV and $\mathrm{DPPC}$ techniques. The difference between the $\triangle \mathrm{E}$ for each technique is likely to be due to the fact that for the DPPC case a more homogenous film is obtained, which is complementary for the detection process, because of the better contact between the chlorophenol and the electrode surface.

The physical characteristics found by SEM in the analyzed films permit to conclude that the CME with the most homogeneous surface and the best film distribution over the electrodic surface is the CME produced by means of DPPC. 
This technique was applied for the first time in this work to modify electrodic surfaces.

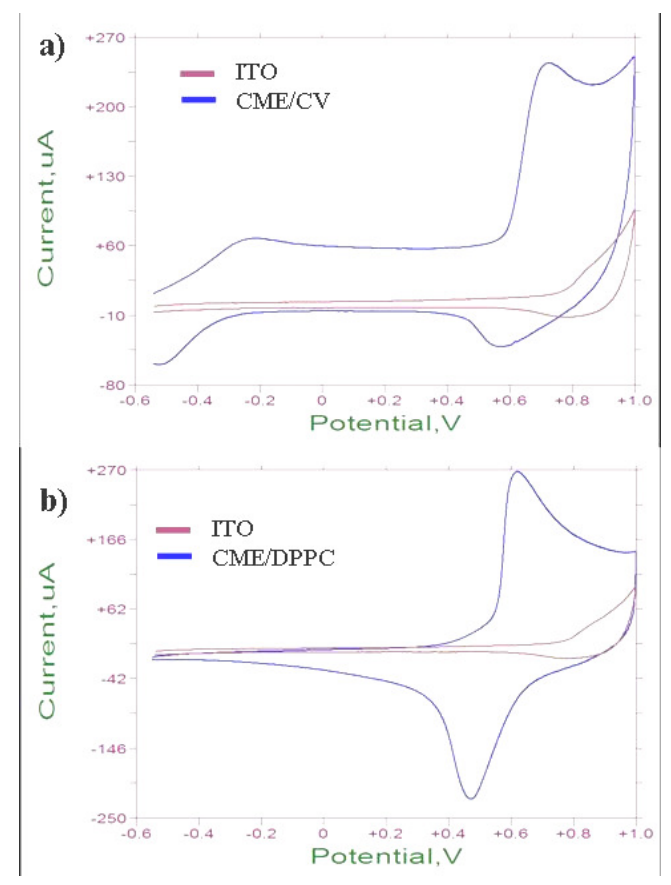

Figure 3. 2,4-DCP detection using: a) CME prepared by $\mathrm{CV}$ as the working electrode (pH 5), b) CME prepared by DPPC as the working electrode ( $\mathrm{pH} 5$ ).

Table 5. Potential peak differences and peak oxidation currents for the 2,4-DCP detection using CME/CV and CME/DPPC.

\begin{tabular}{|c|c|c|}
\hline Technique & $\Delta \mathrm{E}_{\mathrm{p}}(\mathrm{mV})$ & $\operatorname{ip}_{\mathrm{ox}}(\mathrm{mA})$ \\
\hline DPPC & $84.12_{ \pm 12.8}$ & $9.8_{ \pm 0.88}$ \\
\hline Cyclic voltammetry & $202.9_{ \pm 20.5}$ & $6.9_{ \pm 0.91}$ \\
\hline
\end{tabular}

Furthermore, the CME produced by DPPC has the best properties as electrochemical sensor. Table 5 shows that the oxidation current of the 2,4-DCP is higher for DPPC than for CV, which is an indicator of a higher reactivity of the immobilized film obtained by DPPC in comparison with the CV technique. This result agrees with the results of the coulombimetric technique: the CME obtained by DPPC has higher values of $\Gamma$ than the other CMEs (see Table 4). In other words, it has a higher quantity of immobilized film per electrode surface unit, as well as a higher affinity to the 2,4-DCP.

\section{Conclusions}

The electrode modification technique has a significant influence on the physicochemical properties of the immobilized film. In this work we applied for the first time the DPPC technique to modify an ITO electrode surface. The application of DPPC leds to CMEs with a higher capacity to detect 2,4-DCP than 
that of the CMEs obtained by chemisorption, chemisorption assisted by electric field, and CV.

\section{Acknowledgements}

The authors acknowledge the financial support provided by CONACYT to the project 42943-Q "Ultrasound and environment: Sonochemical destruction of chlorated phenolic derivatives", and also the support provided by PAICYT-UANL to the project CA128705 "Sonochemical destruction of chlorated phenolic derivatives".

\section{References}

1. Hindi Centre Ecologic Science, Environmental Protection Guide, Issue III, Environmental Standard Catalog, http://ces.iisc.ernet.in/energy/HC270799/HDL/ENV/envsp/Vol314j.htm, Consulted on August 2005.

2. J. Manríquez, Electrocatálisis de la óxido-reducción de especies contaminantes por complejos y macrociclos de níquel y cobalto inmovilizados sobre electrodos de carbón vítreo, Thesis, Universidad de Guanajuato, Guanajuato, Gto., México, 1999.

3. F. Bedioui, Investigation Balance Results for the Period 1996-2000. Analytical Chemistry and Electrochemistry Lab., Ecole National Supérieure du Chimie in Paris (ENSCP).

http://www.enscp.jussieu.fr/labos/LECA/Research/bedioui/Rap_activit.htm, Consulted on September 2005.

4. I. Mayer, M.N. Eberlin, D.M. Tomazela, J. Braz. Chem. Soc. 16-3A (2005) 418-425.

5. M. Vilas-Boas, E.M. Pereira, J. Electroanal. Chem. 538-539 (2002) 47-58.

6. P.T. Kissinger, W.R. Heineman, Laboratory Techniques in Electroanalytical Chemistry. Marcel Dekker, 1996, Chapter 13, New York, NY.

7. J.L. Jiménez, L.M. Blanco, Modificación Química de Superficies de Carbón Vitreo con el Complejo Ni-trietilendiamina para Supervisar la Degradación Anódica de Compuestos Fenólicos Clorados. Proceedings of XIX Congreso Nacional de la Sociedad Mexicana de Electroquímica, México, 2004.

8. H. Feng, B. Tu, Y.Q. Li, Y.P. Lu, Z. Jin, Acta Crystallographica, 2006, E62, m1405-m1407. 